\section{Antineutrophil cytoplasmic antibodies: appropriate use and interpretation}

It was with much interest that we read the letter of Novikov et $a l^{1}$ on testing for antineutrophil cytoplasmic antibodies (ANCAs) in patients with ANCA-associated vasculitides (AAV) and other diseases. In their letter, the authors (1) share their experience with direct testing for proteinase-3 (PR3) ANCA and myeloperoxidase (MPO) ANCA and (2) raise some important issues regarding interpretation of ANCA test results.

Novikov et al $^{1}$ abandoned indirect immunofluorescence (IIF) for ANCA screening more than 10 years ago and since then have been directly testing for PR3-ANCA and MPO-ANCA by immunoassay. They identified antibodies in $96.9 \%$ of patients with microscopic polyangiitis (MPA), in $72.7 \%$ of patients with granulomatosis with polyangiitis (GPA) and in $92.2 \%$ of patients with renal GPA. These results are in line with the results obtained in a recent multicentre study by the European Vasculitis Study Group ${ }^{2}$ and confirm that patients with GPA with localised (limited) disease can be ANCA negative. ${ }^{3}$ More importantly, the experience of Novikov et $a l^{1}$ validates that a strategy based on the use of antigen-specific immunoassays instead of IIF is feasible and dependable for ANCA detection in AAV. This supports a revision of the international consensus on ANCA testing in AAV, in which antigen-specific immunoassays are recommended to screen for ANCA in AAV. Novikov et al, however, do not provide data on patients that were not diagnosed with AAV, which of course is essential with respect to the correct judgement of the proposed testing procedure. Also, it would be of interest to have information on the type of test that was used.

Novikov et $a l^{1}$ also touched on some essential points regarding ANCA testing and interpretation, which we endorse. First, ANCA testing should be performed in the right clinical context, that is, a high pretest probability for AAV. Gating policies for requesting ANCA have been proposed. ${ }^{4}$ Second, a negative ANCA test result does not exclude AAV (eg, ANCA-negative limited GPA, see above). Third, ANCA help with the diagnostic workup of AAV and should be interpreted together with clinical and histological data. Fourth, one should recognise that ANCA can be found in conditions other than AAV. For example, infections such as endocarditis can induce PR3-ANCA and MPO-ANCA and can mimic ANCA-related glomerulonephritis. ${ }^{5}$ Therefore, infection should be excluded before a diagnosis of $\mathrm{AAV}$ is established. Also drugs, such as hydralazine, propylthiouracil and levamisole-adulterated cocaine, can induce secondary forms of AAV. ${ }^{6}$

Based on associations with genetic background and epidemiology, it has been suggested that ANCA specificity (PR3-ANCA vs MPO-ANCA) could be better than clinicopathological diagnosis (GPA, MPA) for defining homogeneous groups of patients. ${ }^{7}$ We agree with Novikov et al ${ }^{1}$ that this discussion cannot be finalised yet.

In some gastrointestinal disorders such as ulcerative colitis, autoimmune hepatitis and primary sclerosing cholangitis, atypical ANCA can be detected by IIF. $^{9}{ }^{10}$ As the target antigen is not known, specific immunoassays are not available. It has recently been shown that with a sensitive chemiluminescence assay, PR3-ANCA can be found in patients with ulcerative colitis ${ }^{11}$ and primary sclerosing cholangitis. ${ }^{12}$ It is therefore important to distinguish ANCA requests in the context of AAV from requests in the context of gastrointestinal disease.
In conclusion, Novikov et $a l^{1}$ addressed some important points related to correct ANCA use and interpretation.

\section{Jan Damoiseaux, ${ }^{1}$ Elena Csernok, ${ }^{2}$ Niels Rasmussen, ${ }^{3}$ Jan-Willem Cohen Tervaert, ${ }^{4}$ Xavier Bossuyt ${ }^{5,6}$}

${ }^{1}$ Central Diagnostic Laboratory, Maastricht University Medical Center, Maastricht, The Netherlands

${ }^{2}$ Department of Internal Medicine, Rheumatology and Immunology, University Teaching Hospital Kirchheim, Vasculitis-Center Tübingen-Kirchheim, Kirchheim-Teck, Germany

${ }^{3}$ Department of Autoimmune Serology, Statens Seruminstitute, Copenhagen, Denmark

${ }^{4}$ Department of Internal Medicine, Maastricht University, Maastricht, The Netherlands

${ }^{5}$ Department of Microbiology and Immunology, KU Leuven, Leuven, Belgium

${ }^{6}$ Department of Laboratory Medicine, University Hospitals Leuven, Leuven, Belgium

Correspondence to Dr Xavier Bossuyt, Laboratory Medicine, University Hospitals Gasthuisberg, Herestraat 49, Leuven 3000, Belgium; Xavier.Bossuyt@uzleuven.be

Contributors All authors contributed to review the manuscript.

Competing interests None declared.

Provenance and peer review Commissioned; internally peer reviewed.

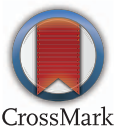

To cite Damoiseaux J, Csernok E, Rasmussen N, et al. Ann Rheum Dis 2017;76:e24.

Received 8 December 2016

Accepted 10 December 2016

Published Online First 2 January 2017

\section{Linked}

http://dx.doi.org/10.1136/annrheumdis-2016-210890

Ann Rheum Dis 2017;76:e24. doi:10.1136/annrheumdis-2016-210908

\section{REFERENCES}

1 Novikov P, Smitienko I, Bulanov N, et al. Testing for antineutrophil cytoplasmic antibodies (ANCAs) in patients with systemic vasculitides and other diseases. Ann Rheum Dis 2017;76:e23.

2 Damoiseaux J, Csernok E, Rasmussen N, et al. Detection of antineutrophil cytoplasmic antibodies (ANCAs): a multicentre European Vasculitis Study Group (EUVAS) evaluation of the value of indirect immunofluorescence (IIF) versus antigen-specific immunoassays. Ann Rheum Dis 2017;76:647-53.

3 Holle JU, Gross WL, Holl-Ulrich K, et al. Prospective long-term follow-up of patients with localised Wegener's granulomatosis: does it occur as persistent disease stage? Ann Rheum Dis 2010;69:1934-9.

4 Savige J, Gillis D, Benson E, et al. International Consensus Statement on Testing and Reporting of Antineutrophil Cytoplasmic Antibodies (ANCA). Am J Clin Pathol 1999;111:507-13

5 Mahr A, Batteux F, Tubiana S, et al. IMAGE Study Group. Brief report: prevalence of antineutrophil cytoplasmic antibodies in infective endocarditis. Am I Clin Pathol 2014:66:1672-7.

6 Pendergraft WF, Niles JL. Trojan horses: drug culprits associated with antineutrophil cytoplasmic autoantibody (ANCA) vasculitis. Curr Opin Rheumatol 2014;26:42-9.

7 Cornec D, Cornec-Le Gall E, Fervenza FC, et al. ANCA-associated vasculitis-clinical utility of using ANCA specificity to classify patients. Nat Rev Rheumatol 2016;12:570-9.

8 Hilhorst M, van Paassen P, Cohen Tervaert JW, Limburg Renal Registry. Proteinase 3-ANCA vasculitis versus myeloperoxidase-ANCA vasculitis. J Am Soc Nephrol 2015;26:2314-27.

9 Bossuyt X. Serologic markers in inflammatory bowel disease. Clin Chem 2006;52:171-81

10 Liberal $R$, Grant CR, Longhi MS, et al. Diagnostic criteria of autoimmune hepatitis. Autoimmun Rev 2014;13:435-40.

11 Mahler M, Bogdanos DP, Pavlidis P, et al. PR3-ANCA: a promising biomarker for ulcerative colitis with extensive disease. Clin Chim Acta 2013:424:267-73.

12 Stinton LM, Bentow C, Mahler M, et al. PR3-ANCA: a promising biomarker in primary sclerosing cholangitis (PSC). PLOS ONE 2014:9:e112877. 